\title{
Uso de atividade Wiki como introdução à relatividade Galileana em turmas de nível médio: Relato de uma experiência.
}

Diogo Chitolina, Instituto Federal de Educação, Ciência e Tecnologia de Santa Catarina, diogo.chitolina@ifsc.edu.br

\author{
Paulo José Sena dos Santos, Universidade Federal de Santa Catarina, \\ paulo.sena@ufsc.br
}

\section{Resumo}

Neste trabalho, apresentamos, descrevemos e analisamos a elaboração e aplicação de uma atividade wiki, apoiada na plataforma Moodle, cujo objetivo visa promover uma discussão inicial sobre a relatividade galileana em turmas de nível médio. Em face à tendência de utilização das TDIC nos processos de ensino-aprendizagem a wiki apresenta-se como uma ferramenta importante ao promover a produção colaborativa de hipertextos. A atividade foi aplicada em duas turmas de terceiro ano do ensino médio. A análise dos hipertextos desenvolvidos mostrou o envolvimento dos estudantes com a atividade, a presença de elementos importantes ao entendimento da relatividade galileana, assim como a necessidade do aprofundamento de alguns conceitos. Os resultados obtidos permitem afirmar que esta ferramenta pode ser útil na elaboração de atividades que incentivem o estudante a construir de forma colaborativa o conhecimento escolar, transformando-o em sujeito ativo nesta ação e pertencente ao contexto educacional no qual está inserido.

Palavras-chave: Wiki, Relatividade Galileana, Ambiente Virtual de Ensino e Aprendizagem.

\section{Abstract}

In this work we will describe and analyze an application of an wiki made in a Moodle platform. The objective of this activity was to promote a discussion about Galileo's relativity at third year high school students. The analysis of the hypertext built by students showed that they participated of this construction and the presence of important elements to the understanding of the concepts involved. But we also noted the necessity to discuss more some concepts. The results also show that the wiki can be very useful in activities to promote a collaborative construction of knowledge.

Key-words: Wiki, Galilean Relativity, Virtual Learning Environment.

\section{Introdução}

O uso das Tecnologias Digitais de Informação e Comunicação (TDIC) têm apresentado importância cada vez maior na mediação das relações da sociedade moderna. Nos ambientes formais de aprendizagem não poderia ser diferente. Observa-se a existência de propostas e tentativas de transformar ferramentas como o computador, o tablet, o smartphone, dentre outras, conectadas à internet, parte do cotidiano escolar brasileiro. Isto acaba orientando uma modificação das práticas pedagógicas a fim de associar estas ferramentas às experiências de ensino e aprendizagem. 
No ambiente escolar, o emprego das TDIC pressupõe um propósito que vai muito além do simples caráter de consulta rápida de informações. A "web 2.0" trouxe a possibilidade de transformar as TDIC em instrumentos eficazes nos processos de aprendizagem. Dentro desta perspectiva, observa-se o afloramento da aplicação de ambientes virtuais de ensino e aprendizagem (AVEA) como auxiliares nos processos educativos presenciais, estes cujo emprego já se encontra consolidado nos cursos de modalidade à distância.

Entre meio as diversas plataformas que possibilitam a criação de AVEAs, tem tido destaque o Moodle (Modular object-oriented dynamic learning enviroment). Ele se encaixa na realidade brasileira por ser um software livre, grátis e de fácil customização, com tradução para o português, ampla quantidade de desenvolvedores, uso facilitado pelo seu caráter modular e por oferecer uma gama variada de ferramentas. O Moodle permite enriquecer e flexibilizar a dimensão espaço-temporal da escola. Conforme Figueira, A; Figueira, C e Santos (2009), o Moodle agrega ferramentas que possibilitam a criação e disponibilização de comunidades de aprendizagem online, onde os participantes podem, por exemplo, comunicar-se entre si de forma síncrona (chat) e assíncrona (fórum, e-mail, mural, etc.), submeter trabalhos, efetuar testes online, realizar trabalhos em grupo de forma colaborativa (wikis, Workshops), responder questionários, assistir vídeo-aulas, tomar contato com lições hipermidiáticas, além de permitir que outros aplicativos didáticos e ferramentas externas sejam nele anexados.

Estes recursos didáticos que o Moodle abarca têm grande potencial para o ensino da física pois proporcionam ao professor mais uma oportunidade de diversificação de suas metodologias. É importante ressaltar que o AVEA se constitui como um ambiente que pode permitir uma ruptura com uma abordagem escolar tradicional. Isto é percebido quando o papel do professor deixa de ser o transmissor do conhecimento e passa a ser o de orientador que faz a ligação entre os estudantes, suas necessidades, seu papel na sociedade e os conhecimentos, proporcionando situações e discussões que de forma colaborativa direcionam os estudantes ao alcance de objetivos ligados à aprendizagem.

Dentre as diversas ferramentas oferecidas pelo Moodle, a wiki destaca-se pelo seu caráter colaborativo. Para Abegg, Bastos e Muller (2010), o ato de colaborar pressupõe que, ao trabalhar em conjunto, dois ou mais sujeitos trocam ideias e experiências entre si, dialogam e problematizam as situações e como fruto desta interação mútua, novos conhecimentos vêm à tona. Os autores ainda indicam que o termo wiki é utilizado para denominar um software capaz de armazenar um conjunto de páginas web que, quando interligadas, estabelecem um hipertexto ou uma hipermídia. Além do mais, a wiki permite a edição on-line colaborativa de hipertextos num formato onde as páginas, naturalmente, são vinculadas a outras páginas permitindo uma navegação não linear e constituindo denominado pelos autores de mídia-hipertextual.

Nesse contexto, a wiki apresenta-se como uma ferramenta que permite a promoção da autonomia dos estudantes através da construção colaborativa de hipermídias. Abegg e Bastos (2012), observam que os estudantes de física, muitas vezes, estão inseridos em uma cultura de produção escolar individualizada. Segundo o diagnóstico dos autores, os estudantes são incentivados pelos docentes a produzir respostas ou resolver listas de exercícios de forma individual. Por permitir que os estudantes produzam hipertextos de forma colaborativa, participativa e interacionista é que as atividades wiki possibilitam o distanciamento dos tradicionalismos no ensino da disciplina, inserindo os estudantes em situações dialógico-problematizadoras quando os coloca como sujeitos ativos no processo de ensino e aprendizagem.

Este artigo apresenta as análises e resultados de uma proposta de atividade wiki aplicada em duas turmas de ensino médio. A atividade teve como objetivo a criação de 
hipertextos colaborativos que, a partir de leituras de fragmentos de textos selecionados do "Diálogo sobre os dois máximos sistemas do mundo Ptolomaico e Copernicano", aborde o contexto histórico e científico no qual Galileu esteve inserido a fim de contextualizar suas ideias e experiências apresentadas ao longo das leituras indicadas.

\section{O uso de atividades wiki no ensino de ciências}

Apesar deste tipo de ferramenta ter potencial de aplicação como metodologia didática ao longo de aulas de ciências, poucas experiências são relatadas na literatura. Abaixo apresenta-se uma revisão de experiências de utilização de atividades wiki conforme relatadas por Abegg e Bastos (2012), Abegg, Bastos e Muller (2010), Figueiredo, Dias e Chagas (2009), Serres e Basso (2008) e Pinho, Ribas e Lahn (2007).

Prado, Ribas e Lahm (2007) propuseram a construção de um material didático colaborativo para apoiar as aulas na disciplina de Geometria Espacial em um curso de Licenciatura em Matemática, na modalidade à distância, em uma universidade federal no Estado do Rio Grande do Sul, através da utilização de um ambiente wiki. A análise foi realizada através de relatos e discussões realizados em chats e fóruns e pelas postagens no ambiente. As declarações dos alunos apontaram para: a importância do material didático para auxiliar a organização e a reorganização de suas aprendizagens; e uma participação mais ativa nos ambientes virtuais, através das discussões de questões relativas ao conteúdo com colegas e professores. Estes aspectos, para os autores, permitiram um reforço na autonomia dos estudantes devido a criação de situações que privilegiaram a interatividade, a colaboração e a afetividade.

A investigação de Serres e Basso (2008) concentrou-se na contribuição de ambientes virtuais para a aprendizagem de Matemática, assim como aspectos relacionados com as questões envolvendo aprendizagem de conceitos da disciplina. Eles utilizaram a ferramenta pbwiki (site que permite o trabalho colaborativo), pois permite aos usuários editarem rapidamente em um navegador de internet, além de permitir modificações de conteúdo ainda que o usuário não seja o autor. Os autores publicaram desafios, relacionados aos conceitos discutidos, que os estudantes deveriam resolver e descrever o processo de solução em seus pbwikis. Ao final do ano letivo os autores relataram que: o uso da ferramenta favoreceu: as interações entre alunos-alunos e professores-alunos; uma melhora na escrita envolvendo conceitos de Matemática; a compreensão dos conceitos presentes nos desafios; e um crescimento em termos de aprendizagem.

No relato de Figueiredo, Dias e Chagas (2009) os autores descrevem a aplicação de um trabalho envolvendo 60 estudantes de uma escola secundária privada em Portugal. Neste trabalho, os estudantes, divididos em grupos menores, deveriam discutir em uma atividade wiki as interpretações físicas de situações reais ou fenômenos naturais previamente escolhidos. Como primeira constatação, os autores indicam a estranheza dos estudantes ao perceber que teriam liberdade para escolher o assunto a ser analisado. Entretanto, uma vez aceita a ideia, os estudantes foram capazes de escolher temas que permitiram desde uma análise geral das leis de movimento até a procura de respostas para

\footnotetext{
${ }^{1}$ GALILEI, Galileu. Diálogo sobre os dois máximos sistemas do mundo ptolomaico e copernicano. São Paulo: Editora 34, 2011. 887 p. Tradução de: Pablo Rubén Marioconda.
} 
as situações escolhidas. Conforme os autores, três grupos limitaram a utilização da wiki como repositório de conteúdo, enquanto que os demais grupos entenderam a sistemática da wiki ao adicionar figuras, vídeos, animações, encadear páginas, além de resolver problemas relacionados à dificuldade de inserção de equações demonstrando uma excelente apropriação do uso da ferramenta ao apresentar aumento da qualidade científica das inserções à medida que as wikis evoluíram.

Apesar de apontarem o "medo" inicial de trabalhar com uma nova ferramenta como uma dificuldade, os estudantes gostaram da iniciativa e indicaram como aspectos positivos a facilidade de colaboração à distância, a possibilidade de construção e reconstrução de conteúdos e a orientação dos professores envolvidos. Os autores ainda relataram aumento na motivação, interesse e empenho dos estudantes durante a realização do trabalho e concluem sua análise apontando com principais vantagens: a "qualidade" do acompanhamento que a ferramenta permite (relacionada ao apoio do professor mesmo à distância) e a contribuição para a elevação da autoestima dos estudantes que regularmente acreditam que seu trabalho possui uma qualidade inferior. Os autores indicam desvantagens no uso da wiki relacionadas a dificuldade de comunicação devido a problemas de natureza técnica (como dificuldade de acesso) e ao tempo necessário para o domínio da ferramenta.

No relato de Abegg, Bastos e Muller (2010) os autores implementaram ações através do processo de Planejamento, Execução e Avaliação (PEA) ao longo de um semestre letivo da disciplina de "Didática I" do curso de Licenciatura em Física da Universidade Federal de Santa Maria (UFSM). Para os autores, as wikis potencializam investigações baseadas na aprendizagem como um processo cíclico-espiralado de investigação, criação, discussão e reflexão. Portanto, neste processo PEA, na fase de planejamento foi compartilhado o contrato didático; na fase de execução foram realizadas as ações de produção colaborativa mediada pelo wiki do Moodle, e a fase de avaliação foi marcada pela aplicação de surveys ao final da produção de cada ciclo além da análise da participação nos momentos de diálogos-problematizadores realizados presencialmente. Os autores destacaram que: (I) após o vencimento de dificuldades e resistências os estudantes tiveram uma participação ativa caracterizada pela proposição de novos parágrafos ou a edição dos existentes; (II) os alunos sentiram-se capazes - em termos do desenvolvimento de competências e habilidades - de produzir um material de divulgação científico-tecnológica. Os principais obstáculos apontados estão relacionados ao modo de produção escolar, uma vez que os estudantes estão acostumados com tarefas individuais; e as dificuldades com o uso da ferramenta wiki.

Abegg e Bastos (2012) relatam experiências junto a turmas de "Didática I", "Didática II" e "Ensino de Física mediado pelas tecnologias" do curso de licenciatura em Física da UFSM. Apesar dos autores relatarem que parte dos estudantes já haviam realizado atividades mediadas por TICs, as dificuldades de manuseio prático da ferramenta ainda figuraram como obstáculo para a realização da atividade proposta. Outro obstáculo indicado pelos autores consiste na mudança no modo de produção escolar científico-tecnológico, uma vez que no curso citado, tradicionalmente existe ênfase na resolução de problemas didáticos, muitas vezes extraídos de livros texto, com baixa ou nenhuma mediação por TICs. Os autores apontaram que dentre as ferramentas de atividades colaborativas, a wiki ganha destaque em termos da produção hipermidiática, porém, mesmo no âmbito da educação à distância, a produção individualizada ainda é 
hegemônica. Os autores indicam também um aumento significativo da participação colaborativa dos estudantes e na autoria e coautoria na resolução de atividades de estudo. Segundo os autores, “[...] ainda que ao considerar o tripé diálogo-problematizador, colaboração e autonomia, [...] a mediação tecnológica educacional wiki do Moodle é mais que um viável-possível [...] se torna um inédito-viável, se conduzida por docência investigativa com boa fluência tecnológica.” (p. 754).

\section{$O$ cenário}

A atividade wiki aqui relatada faz parte de um projeto maior cujo objetivo consistiu no desenvolvimento de um AVEA denominado: "Construção do conceito de relatividade voltado para o ensino da relatividade". O projeto ateve-se a encaminhar os estudantes envolvidos pelos conceitos fundamentais da teoria da relatividade, porém, tendo como pano de fundo o processo de evolução do conceito de relatividade ao longo do desenvolvimento científico.

A atividade wiki foi aplicada para um público-alvo de 49 estudantes, compreendidos em uma faixa etária que variou de 15 a 18 anos, matriculados no terceiro ano do curso técnico integrado em agroindústria de uma instituição federal de ensino localizada em uma região de fronteira no estado de Santa Catarina. Para a realização desta atividade, os estudantes foram subdivididos em duas turmas que, ao longo deste texto serão diferenciadas como "turma 1" com 30 estudantes e "turma 2"com 19 estudantes. Os estudantes dispuseram de três encontros semanais presenciais, cada um com 110 minutos de duração, além de quatro semanas de acesso extraclasse para edições na atividade.

\section{A atividade wiki}

Como introdução à wiki, os estudantes foram convidados a realizar uma leitura de trechos selecionados da obra "Diálogo"2 de Galileu: Estes trechos foram apresentados aos estudantes em uma versão digital, através do Sway (C) da Microsoft $\mathrm{C}$, ferramenta que permite a criação de apresentações na web que se adaptam a tela de qualquer dispositivo digital. Os trechos selecionados apresentam os diálogos construídos por Galileu para retratar elementos do seu conceito de relatividade.

Após um breve esclarecimento sobre o formato dos escritos de Galileu e da indicação da leitura, os estudantes foram direcionados à atividade. Esta consistia na produção de páginas wiki, onde deveriam ser discutidos colaborativamente a vida e o contexto histórico de Galileu, assim como as ideias e experiências relatadas por ele ao longo das leituras sugeridas. Como orientação para a realização da atividade, aconselhouse que os estudantes respondessem, durante a construção colaborativa do hipertexto, aos seguintes questionamentos norteadores:

1) Qual foi o principal objetivo de Galileu ao propor a experiência da bola solta do alto do mastro do navio?

2) Há diferença no fenômeno caso o navio esteja em repouso ou em movimento em relação a praia?

3) $\mathrm{O}$ que Galileu pretendia ao relacionar o movimento do navio com o movimento do planeta Terra?

4) $\mathrm{O}$ que acontece com os fenômenos físicos quando observados de dentro do navio sem que se possa "olhar para fora"?

${ }^{2}$ Op. Cit. 
5) Há diferença caso o navio não esteja movimentando-se com velocidade constante, ou seja, acelerado?

6) Qual é a diferença entre um referencial inercial de um referencial não inercial?

Cada turma deveria, na conclusão da atividade, apresentar uma página wiki, contendo hyperlinks, vídeos, animações, textos, citações e demais ferramentas que a linguagem HTML permite incorporar. Deve-se levar em consideração as permissões de acesso a atividade que cada turma desfrutava. Ao mesmo tempo em que os membros de uma das turmas poderiam visualizar e editar sua respectiva wiki, ou seja, participavam de forma ativa na construção da sua página, tinham a permissão de observar passivamente $o$ andamento da construção da página wiki referente a outra turma.

\section{Metodologia}

Neste trabalho nos concentramos em realizar uma análise qualitativa da produção hipertextual. Segundo Flick (2009, p. 8), este tipo de análise permite esmiuçar "a forma como as pessoas constroem o mundo a sua volta, o que estão fazendo ou o que está lhes acontecendo [...]".

Apesar da pesquisa qualitativa ser criticada pela subjetividade e pelo envolvimento emocional do pesquisador (MINAYO, 2001 apud GERHARDT; SILVEIRA, 2009, p.32), para Flick (2009) este tipo de metodologia preenche uma lacuna quando não é possível realizar de forma clara o isolamento e a identificação das variáveis de estudo. Esse tipo de análise permite: ter acesso as experiências, interações e documentos em seu contexto natural; desenvolver hipóteses e conceitos, além de seus refinamentos, no processo da pesquisa.

Um aspecto importante relacionado à pesquisa qualitativa sugere que o pesquisador se apresente como o principal instrumento de coleta de dados (BOGDAN \& BIKLEN apud CAMARGO, 2005, p. 78). Isto permite que o pesquisador realize uma análise contextualizada e simultânea à coleta dos dados, onde suas experiências, concepções e posicionamentos podem interferir tanto na aplicação da pesquisa, quanto na análise dos dados.

Portanto, nesse trabalho procuramos identificar a presença de aspectos importantes para o entendimento do trabalho de Galileu, como a relevância do uso do referencial para descrição dos movimentos e a indistinguibilidade entre o repouso e o movimento uniforme para referenciais inerciais, além de verificar elementos que indicam a participação colaborativa dos estudantes na produção e na criação de relações entre os conteúdos.

\section{Discussão}

A execução da atividade durante os períodos presenciais pode ser dividida em duas etapas. A primeira, que compreende um encontro semanal, foi dedicada aos esclarecimentos sobre a realização da atividade e à leitura dos trechos recortados do "Diálogo". Já a segunda etapa, que compreende os dois encontros semanais restantes, foi dedicada à construção do hipertexto colaborativo.

$\mathrm{Na}$ primeira etapa, os estudantes relataram dificuldades de interpretação e entendimento durante as leituras. Tais dificuldades podem ser justificadas pelo vocabulário complexo empregado por Galileu Galilei. Numa tentativa de amenizar este 
problema, recomendou-se que os estudantes utilizassem a ferramenta "glossário", presente no Moodle, para a construção colaborativa do significado contextualizado dos termos mais complexos. Ambas as turmas fizeram uso desta ferramenta que, no final da atividade, apresentou a definição de aproximadamente 30 termos.

Uma particularidade desta etapa foi o grande número de vezes em que o professor foi chamado para colaborar na elucidação das cenas descritas nos diálogos. Considerando que a abordagem através da imaginação de cenários seguida de sua discussão seja amplamente utilizada nas aulas e materiais didáticos, as dúvidas levantadas mostram a importância e a necessidade da presença do professor orientador durante a aplicação deste tipo de atividade.

Na segunda etapa, os estudantes dedicaram-se à construção das páginas $\mathrm{HTML}^{3}$ no formato wiki. Ambas as turmas apresentaram preocupação em construir uma página principal a partir da qual o texto ramificou-se por meio de uma cadeia de hiperlinks, bastante semelhante a uma página da Wikipédia, modelo utilizado para exemplificar o formato da atividade. Também se observou que as duas turmas empregaram vídeos disponíveis no Youtube $\mathbb{C}$, além de imagens e animações para ilustrar e contextualizar a produção textual, caracterizando assim uma integração hipermidiática, subsídio potencializador do processo de ensino que, segundo Fruet (2010), possibilita a interação dialógico-problematizadora, a interatividade e o desenvolvimento da flexibilidade cognitiva.

O acompanhamento e avaliação das atividades wiki foi realizado através do controle de versões, onde o professor tem acesso ao histórico de edições das páginas web construídas. Por meio dele, por exemplo, é possível controlar a frequência de alterações de uma página, onde se observa a participação individual ou em grupo nas alterações do texto. Também permite verificar como foram feitas estas alterações, permitindo a análise do caráter colaborativo da construção textual.

Ao analisar o controle de versões, perceberam-se peculiaridades que por vezes assemelharam e por outras distinguiram as turmas. Em relação ao processo de construção do texto, constatou-se que ambas as turmas apresentaram boa parte de suas argumentações baseadas em materiais disponíveis na internet, muitas vezes fazendo citações literais sem apresentar a devida referência. Com o intuito de minimizar este problema, sugeriu-se que cada página criada deveria conter em sua estrutura as fontes de informação utilizadas durante a argumentação no texto.

Durante o período em que a kiwi esteve disponível para edição, foram contabilizadas 7117 visualizações da atividade, das quais, $71 \%$ foram realizadas a partir da escola durante o horário normal da classe. Ao observar que $29 \%$ das visualizações da atividade aconteceram a partir de computadores localizados fora do ambiente escolar e em horário extraclasse, evidencia-se a importância do período presencial para a execução da atividade. Por outro lado, este fato não minimiza a relevância da possibilidade de acesso à atividade pelos estudantes fora da sala de aula.

Já no tocante à colaboração, enquanto a turma 1 apresentou um texto cuja construção contou com um maior número de participantes editando uma mesma página, a turma 2 exibiu um texto que foi escrito de forma mais individualizada, porém, visualizado e verificado mais vezes pelos membros da equipe. Contudo, as duas turmas

${ }^{3}$ Abreviação em inglês para: "linguagem de marcação de hipertexto", utilizada para a construção de páginas na web. 
apresentaram textos com caráter colaborativo, sendo que a turma 1 mostrou-se mais cooperativa ao longo da construção enquanto que a turma 2 destacou-se pela produção individualizada, porém averiguada por mais membros da equipe.

Ao longo dos textos, ambas as turmas enfatizaram o contexto histórico e social ao qual Galileu esteve inserido. Apresentaram-no como o "pai da Física moderna" ao apontar suas invenções e contribuições para a ciência, destacaram as concepções ideológicas e filosóficas da época, salientaram sua forma criativa de escrever para evitar as perseguições do Santo Ofício, além de citar sua condenação inquisitorial.

Ao analisar os textos, encontram-se passagens onde é feito o uso do conceito de referencial, como no recorte apresentado no quadro 1 retirado da construção textual da turma 1:

Quadro 1 - Recorte do texto produzido pela turma 1 na atividade wiki ilustrando o uso do conceito de referencial

"Para refletir: Suponha que você é um observador no cais de um porto, e a sua frente há um navio que se move com velocidade constante. Se alguém que estiver no alto do mastro com uma esfera de ferro nas mãos a soltar, onde a esfera irá cair? Pois bem, de acordo com Galileu, a esfera está acompanhando a velocidade do barco e cairá exatamente embaixo do ponto onde foi largada. Para a pessoa que estava dentro do navio, a esfera caiu verticalmente, mas para o observador afastado do navio não, pois se ela caísse verticalmente com o navio em movimento, iria ser em um ponto bem afastado do mastro.[Grifo nosso]. "

Fonte: elaborado pelos autores (2017).

O trecho apresentado no quadro 2, retirado da produção da turma 2, permite constatar o emprego das noções de movimento e repouso ligadas a um referencial.

Quadro 2 - Recorte do texto produzido pela turma 2 na atividade wiki ilustrando o uso do conceito de referencial

"Conclui-se então que a trajetória do corpo, observado do referencial em que ele é abandonado a partir do repouso, é sempre uma linha reta vertical, quando este referencial está em repouso ou se move com uma velocidade horizontal constante em relação a um referencial fixo na superfície da Terra."

Fonte: elaborado pelos autores (2017).

Outro aspecto relevante que se destaca na produção textual aparece quando são analisadas as tentativas de diferenciação entre os referenciais inercial e não inercial. A turma 1 construiu uma página exclusiva para tratar desse conceito e, utilizando o exemplo clássico das pessoas soltas dentro de um ônibus em movimento uniformemente variado, conseguiu apresentar de forma incipiente as diferenças entre os referenciais inercial e não inercial. Pode-se observar no recorte do quadro 3, quando o conceito foi aplicado ao movimento do planeta Terra:

Quadro 3 - Recorte do texto produzido pela turma 1 na atividade wiki referindo-se aos referenciais inercial e não inercial

"A Terra, em virtude do seu movimento de rotação, não pode ser propriamente considerada um referencial inercial. No entanto, para movimentos de pequena duração, pode-se desprezar os efeitos de rotação e considerar a Terra como sendo um referencial inercial".

Fonte: elaborado pelos autores (2017). 
Neste aspecto, o texto da turma 2 apresentou distinção entre os referenciais ao levar em consideração a presença ou a ausência de forças, conforme verificado no recorte do quadro 4.

Quadro 4 - Recorte do texto produzido pela turma 2 na atividade wiki diferenciando referenciais inerciais de não inerciais

"Referenciais não-inercial podem ser distinguidos pela presença de forças. Referencial não-inercial é qualquer referencial que possua movimento de aceleração (não constante)."

Fonte: elaborado pelos autores (2017).

Levando em conta que um dos questionamentos norteadores para a realização da tarefa wiki consistia na caracterização de diferenças entre a classe de referenciais inerciais e a classe dos não inerciais, percebeu-se que os textos não abordaram a diferenciação em sua totalidade. De fato, este era um resultado esperado, tendo em vista que os estudantes ainda não haviam tido contato com tais conceitos de maneira formal. Não obstante, este questionamento desempenhou um papel de reflexão inicial para atividades subsequentes.

Um quesito esperado ao longo do planejamento da atividade teve como foco o incentivo à argumentação sobre a impossibilidade de detecção de um movimento uniforme a partir de um referencial inercial. Todas as leituras indicadas traziam elementos que direcionavam a atenção para essa implicação da relatividade galileana, além dos questionamentos norteadores que também orientavam para esse objetivo. Constataram-se tentativas por parte de ambas as turmas para cumpri-lo. Ao escrever: "O conceito de movimento uniforme e de repouso são conceitualmente idênticos", a turma 2 ensaia discutir essa questão, contudo, não dá continuidade à argumentação. A turma 1 também vai nessa direção quando escreve: "Simplício afirma que não sentimos o movimento de rotação da Terra, pois estamos compartilhando o mesmo deslocamento que ela, por conta da inércia", porém, assim como a outra turma, não apresenta seguimento na argumentação.

Em um outro fragmento, percebemos que a turma 1 novamente procura discutir sobre a impossibilidade de detecção de um movimento uniforme, quando apresenta a seguinte consideração: "As ideias de Simplício defendem que pode-se saber se o navio está em movimento ou não, devido a distância que a bola cairá do mastro", referindo-se à incompatibilidade envolvendo a concepção aristotélica e a concepção galileana de movimento. Entretanto, mais uma vez a argumentação com grande potencial encerra-se sem ser desenvolvida em sua totalidade.

Levanta-se a hipótese de que ao tomar contato com esses tipos de situações e refletir sobre elas enquanto discute e escreve um texto colaborativo, a assimilação dos conceitos envolvidos por parte dos estudantes possa ser facilitada em atividades subsequentes, cujo ponto de partida leve em consideração as limitações argumentativas por eles manifestadas.

\section{Considerações finais}

De modo geral, os dois textos apresentados na conclusão da atividade wiki assinalaram a necessidade de retomada de alguns conceitos por parte do professor. Tanto pelo grau de aprofundamento, visto que a maioria dos tópicos apresentaram discussão de forma breve, quanto pelo fato de não ter sido possível identificar se os estudantes se 
apropriaram desses conceitos realizando as reflexões devidas sobre o tema ao longo da atividade.

Percebeu-se que a atividade contribuiu por revelar-se uma metodologia diferenciada de abordagem dos conceitos da Física. A construção de um texto colaborativo, quando executado com o mesmo interesse por todos os componentes do grupo, exige que sejam feitas pesquisas, leituras, discussões, argumentações, conciliações e releituras, atitudes sempre almejadas no contexto da aprendizagem. Oferecer novas formas de argumentação e posicionamento aos estudantes pode transformar-se num fator de reforço motivacional para a aprendizagem.

O período presencial sinalizou a necessidade de orientação permanente por parte do professor ao acompanhar a produção do texto colaborativo. A primeira avaliação das produções depois de finalizado o prazo estabelecido mostrou a presença de elementos fundamentais para a construção do entendimento dos pontos principais da relatividade de Galileu. Entretanto, também revelou a necessidade da revisão de diversos pontos conceituais, como exemplo uma discussão mais profunda das concepções de força presentes ao longo da evolução do pensamento científico, na diferenciação entre os tipos de referenciais, entre outros.

\section{Referências}

ABEGG, Ilse; BASTOS, Fábio da Purificação. Ensino de física colaborativo mediado pelo wiki do Moodle: descrição e análise de casos de estudo. Cad. Bras, Ens. Fís. V. 29, n. especial 2, p. 729 757, out. 2012.

ABEGG, Ilse; BASTOS, Fábio da Purificação; MÜLLER, Felipe Martins. Ensino-aprendizagem colaborativo mediado pelo wiki do Moodle. Educar em revista, Curitiba, n. 38, p. 205-218. 2010. Disponível em: <http://revistas.ufpr.br/educar/article/download/13129/13530>. Acesso em 17 Jan. 2016.

CAMARGO, Eder Pires de. O ensino de Física no contexto da deficiência visual: elaboração e condução de atividades de ensino de Física para alunos cegos e com baixa visão. 2005. $272 \mathrm{f}$. Tese (Doutorado) - Curso de Doutorado em Educação, Faculdade de Educação, Universidade Estadual de Campinas, Campinas, 2005.

FIGUEIRA, Álvaro; FIGUEIRA, Carmen; SANTOS, Hugo. Moodle: Criação e Gestão de cursos online. 2. ed. Lisboa: FCA, 2009. 259 p.

FIGUEIREDO, Tereza; DIAS, Guida; CHAGAS, Isabel. Wiki: uma ferramenta de trabalho para o ensino de Física. VI Conferência Internacional de TIC, 2009, p. 1343 - 1356.

FLICK, Uwe. Introdução à pesquisa qualitativa. 3. ed. Porto Alegre: Artmed, 2009. 405 p. Tradução de: Joice Elias Costa.

FRUET, Fabiane Sarmento Oliveira. Atividades de estudo hipermidiática mediadas por ambiente virtual de ensino-aprendizagem livre. 2010. 120 f. Dissertação (Mestrado) - Programa de Pósgraduação em Educação, Centro de Educação, Universidade Federal de Santa Maria, Santa Maria, 2010.

GERHARDT, Tatiana Engel; SILVEIRA, Denise Tolfo (Org.). Métodos de pesquisa. Porto Alegre: Ufrgs Editora, 2009. 120 p. Disponível em: $<$ http://www.ufrgs.br/cursopgdr/downloadsSerie/derad005.pdf>. Acesso em: 03 fev. 2017.

PINHO, Denise Sena; RIBAS, Elisângela; LAHM, Regis Alexandre. Ambiente virtual: uma proposta para construção de material didático. Renote: Revista Novas Tecnologias na Educação, Porto Alegre, v. 5, n. 1, p.330-338, jul. 2007. Disponível em: $<$ http://seer.ufrgs.br/index.php/renote/article/view/14211/8134>. Acesso em: 14 dez. 2017.

SERRES, Fabiana Fattore; BASSO, Marcus Vinicius de Azevedo. Wikis: professores e estudantes criando diários virtuais para aprender matemática. Renote: Revista Novas Tecnologias na Educação, Porto Alegre, v. 6, n. 2, p.314-324, dez. 2008. Disponível em: $<$ http://seer.ufrgs.br/index.php/renote/article/view/14673/8581>. Acesso em: 14 fev. 2017. 